This item was submitted to Loughborough's Research Repository by the author.

Items in Figshare are protected by copyright, with all rights reserved, unless otherwise indicated.

\title{
Microstructures and properties of new Sn-Ag-Cu lead-free solder reinforced with Ni-coated graphene nanosheets
}

PLEASE CITE THE PUBLISHED VERSION

http://dx.doi.org/10.1016/j.jallcom.2015.09.178

\section{PUBLISHER}

(C) Elsevier

VERSION

AM (Accepted Manuscript)

\section{PUBLISHER STATEMENT}

This work is made available according to the conditions of the Creative Commons Attribution-NonCommercialNoDerivatives 4.0 International (CC BY-NC-ND 4.0) licence. Full details of this licence are available at: https://creativecommons.org/licenses/by-nc-nd/4.0/

\section{LICENCE}

CC BY-NC-ND 4.0

\section{REPOSITORY RECORD}

Chen, Guang, Fengshun Wu, Changqing Liu, Vadim V. Silberschmidt, and Y.C. Chan. 2019. "Microstructures and Properties of New Sn-ag-cu Lead-free Solder Reinforced with Ni-coated Graphene Nanosheets". figshare. https://hdl.handle.net/2134/19464. 
1 Microstructures and properties of new Sn-Ag-Cu lead-free solder

\section{reinforced with $\mathrm{Ni}$-coated graphene nanosheets}

Guang Chen ${ }^{1,2}$, Fengshun $\mathrm{Wu}^{l^{*}}$, Changqing Liu ${ }^{2 *}$, Vadim V. Silberschmidt ${ }^{2}$, Y.C.

$\mathrm{Chan}^{3}$

1 State Key Laboratory of Materials Processing and Die \& Mould Technology, Huazhong University of Science and Technology, Wuhan 430074, China

2 Wolfson School of Mechanical and Manufacturing Engineering, Loughborough University, $U K$

3 Department of Electronic Engineering, City University of Hong Kong, Tat Chee Avenue, KowLoon Tong, Hong Kong

*Corresponding author: 1 * State Key Laboratory of Materials Processing and Die \& Mould Technology, Huazhong University of Science and Technology, Wuhan 430074, P.R. China, Tel: $+86-27-87558275$

E-mail: fengshunwu@hust.edu.cn

$2^{*}$ Wolfson School of Mechanical and Manufacturing Engineering, Loughborough University, UK, Tel: +44- 1509227681, E-mail: C.Liu@lboro.ac.uk

\section{Abstract}

This paper deals with microstructures and properties of SAC305 lead-free solder reinforced with graphene nanosheets (GNS) decorated with $\mathrm{Ni}$ nanoparticles (Ni-GNS). These Ni-coated GNS nanosheets were synthesized by an in-situ chemical reduction method. After morphological and chemical characterization, Ni-GNS were successfully integrated into SAC305 lead-free solder alloy with different weight fractions $(0,0.05,0.1$ and $0.2 \mathrm{wt} \%)$ through a powder metallurgy route. The obtained composite solders were then studied extensively with regard to their microstructures, wettability, thermal, electrical and mechanical properties. After addition of Ni-GNSs, cauliflower-like $(\mathrm{Cu}, \mathrm{Ni})_{6} \mathrm{Sn}_{5}$ intermetallic compounds (IMCs) were formed at the interface between composite solder joint and copper substrate. Additionally, blocky $\mathrm{Ni}_{3} \mathrm{Sn}_{4}$-GNS hybrids were also observed homogenously distributed in the composite 
solder matrices. Composite solder alloys incorporating Ni-decorated GNSs nanosheets showed slightly reduced electrical resistivity compared to the unreinforced SAC305 solder alloy. With an increase in the amount of Ni-GNS, the composite solders showed an improvement in wettability with an insignificant change in their melting temperature. Mechanical tests demonstrated that addition of $0.2 \mathrm{wt} \% \mathrm{Ni}$-GNS would result in $19.7 \%$ and $16.9 \%$ improvements in microhardness and shear strength, respectively, in comparison to the unreinforced solders. Finally, the added Ni-GNS reinforcements in the solder matrix were assessed with energy-dispersive X-ray spectroscopy, scanning electron microscopy and Raman spectroscopy.

Key words: Ni-coated graphene oxide; Lead-free solder; Wettability; Melting temperature; Mechanical properties; Raman spectrum

\section{Introduction}

Usage of lead in electronics packaging industry has been largely limited because it poses a threat to the environment as well as people's health. As a result, lead-free solders have gained a rapid development opportunity. Since the alloy system of eutectic SAC (Sn-Ag-Cu) has outstanding mechanical strength, reliability and solderability, it is widely acknowledged as the material with greatest potential among those $\mathrm{Pb}$-free solders [1]. Nevertheless, due to the demand for high-performance electronics and the recent miniaturization trend, the need for new electronic interconnecting material which has high robustness and stability is increasing a lot [2]. Hence, in order to fulfil the higher requirements resulted from the current needs of electronic industry; the properties of those existing materials of $\mathrm{Sn}-\mathrm{Ag}-\mathrm{Cu} \mathrm{Pb}$-free solders should be further improved.

In order to promote the performance of a traditional solder alloy, it is potentially feasible to prepare composite solder by introducing foreign reinforcements into the matrix of the solder alloy. A lot of researchers have widely investigated the influence of different foreign reinforcements (such as carbon-based materials, ceramics and 
metals) on the microstructural evolution as well as mechanical and physical properties of solders [3-7]. Due to special chemical and physical features, the carbon-based nano material (e.g. grapheme and carbon Nanotube) have attracted enormous attention of people as an outstanding reinforcement [8-14]. As a result, researches of different fields tend to choose carbon-based nano materials as the reinforcement to form composites [15-18]. Recently, researchers have made a lot of attempts to study the influence brought by carbon-based nano materials' incorporation on the properties of solder alloy [19-21]. Kumar et al. reported that introduction of Single-wall carbon nanotube (SWCNT) improved mechanical and melting property of SAC solders [19]. $\mathrm{Hu}$ et al. [20] prepared a Sn-Zn-Bi/GNS composite solder using a mechanical mixing approach. They reported that the microhardness and shear strength of solder alloys were considerably improved after GNS addition. In addition, the growth rate of IMC in $\mathrm{Cu} /$ composite solder interface was decreased under aging condition. Using a powder-metallurgy processing route, a SAC305/ GNS composite solder was developed by Liu et al. [21]. This composite solder showed an increase in ultimate tensile strength (UTS) but a decrease in the coefficient of thermal expansion (CTE).

However, the added reinforcements, especially non-wettable ones (usually including ceramics and carbon-based materials) are often found to be expelled from a molten solder during a reflow process [22]. To solve this problem and improve the retained ratio of the added reinforcement in the solder matrix, researchers attempted to form a "bridge" between the reinforcement and solder matrix. Some metal nanoparticles (such as $\mathrm{Au}$ and $\mathrm{Ni}$ ) are regarded as ideal "bridge materials" since they are apt to react with Sn-based solder alloys to form IMCs during a soldering process. Silica nanoparticles with an Au layer were synthesized by Mokhtari et al. [23]; they reported that this core-shell structural reinforcement could be wetted by molten solder. Yang et al. [24-25] studied the effect of carbon nanotubes with Ni coating (Ni-CNTs) on mechanical properties and microstructures of solder alloys. Their experimental results indicated that addition of Ni-CNTs contributed to improvement of performance of solder alloys.

To date, however, there were no reports on the effect of Ni-modified graphene on 
performance of lead-free solder alloys. In this study, in view of exceptional physical and chemical characteristics of graphene, multi-layer graphene nanosheets were thus chosen as the basic reinforcement that also served as a carrier for Ni plating. Ni was chosen as the "bridge material" since it could form IMCs by reacting with molten Sn-based solders during soldering process. In addition, it is also widely reported that an appropriate addition of $\mathrm{Ni}$ had a positive effect on microstructure and service performance of solder alloys [26-27].

To understand the effect of Ni-GNS composite reinforcement on performance of the SAC305 solder alloy, an attempt was made to synthesize Ni-GNS reinforcement as well as fabricating SAC305/Ni-GNS nano-composite solders. Further, both the microstructures and physical and mechanical properties of these composite solders were studied in detail. The existence of the doped reinforcement particles in the solder matrix was also confirmed in this work.

\section{Materials and experimental procedures}

\subsection{Materials}

96.5 $\mathrm{Sn}-3 \mathrm{Ag}-0.5 \mathrm{Cu}$ (wt. \%) alloy powder with average particle diameter of $35 \mu \mathrm{m}$, were purchased from Beijing Compo (China). The multi-layer graphene nanosheets provided by JCNANO Materials Tech (China) with size of 3-10 $\mu \mathrm{m}$ and thickness of 5-10 nm, were used as the carrier for Ni plating.

\subsection{Electroless Ni plating}

In this study, the synthesis of Ni-GNS process included three steps: (1) ultrasonic dispersion, (2) sensitization and activation, and (3) electroless Ni plating. All these three steps are shown in a schematic diagram in Fig 1.

In order to improve the dispersion of GNS nanosheets in chemical reagents, the as-purchased GNS nanosheets were first ultrasonically dispersed in ethanol solution (step 1). After that, the nanosheets were further sensitized and activated subsequently 
112 in $\mathrm{SnCl}_{2}(10 \mathrm{~g} / \mathrm{L})$ and $\mathrm{PdCl}_{2}(0.5 \mathrm{~g} / \mathrm{L})$ solutions (step 2). In the Ni-plating process (step

113 3), $\mathrm{NiSO}_{4}$ was used as a source of $\mathrm{Ni}^{2+}$ while $\mathrm{N}_{2} \mathrm{H}_{4} \cdot \mathrm{H}_{2} \mathrm{O}$ was a reducing agent. After

114 Ni plating, the Ni-coated GNSs were filtered in a centrifugal filter and dried in a 115 vacuum furnace at $50^{\circ} \mathrm{C}$ for $24 \mathrm{~h}$. The components of the plating solution are listed in 116 Table1 together with experimental conditions. Morphology characterization of 117 Ni-coated graphene nanosheets was performed with a FE-SEM (Sirion 200) system 118 together with an Energy Disperse Spectroscopy (EDS).

\subsection{Synthesis of nanocomposite solders}

In order to prepare composite solders, SAC305 Pb-free solder powders were mixed homogeneously with Ni-GNS nanosheets which have different weight fractions $(0 \%, 0.05 \%, 0.10 \%$ and $0.20 \%)$ in a planetary ball mill for 20 hours at speed of 180r/min. Specifically, to avoid impurities (especially, other metal elements) introduced from milling jar or milling balls, the super-hard zirconia milling jar and balls were employed as the milling media. Then, the ball-milled mixture was uniaxially compacted into solder billets before sintered in a vacuum atmosphere. Finally, those solder billets which had been sintered were rolled into the solder foils, the thickness of which was $200 \mu \mathrm{m}$. For the convenience of mechanical, wettability and microstructural analysis, these solder foils were further formed into solder balls $(800 \mu \mathrm{m}$ in diameter) in a reflow oven. Additionally, the as-rolled solder foils and the as-sintered solder billets were subjected to electrical and thermal testing.

\subsection{Characterization methods for composite solder}

For microstructural observation, solder balls were firstly mounted in epoxy before grinding and polishing. The metallographic etching reagent is constituted by the mixture of ethanol and hydrochloric acid $(99.5$ vol. \% ethanol and 0.5 vol. \% hydrochloric acid). The newly formed IMCs at the interface (or in the solder matrices) were observed using an environmental scanning electron microscope (ESEM Quanta 200). 
Differential scanning calorimeter (DSC) was employed to determine the melting

140

141

142

143

144 points of plain and composite solders. The solder foils whose weight ranges from $5 \mathrm{mg}$ to $10 \mathrm{mg}$ are used as specimens for DSC testing. The heating rate during the test was $10^{\circ} \mathrm{C} / \mathrm{min}$, and the highest heating temperature reached up to $250^{\circ} \mathrm{C}$. A four-point probe system was employed to measure the electrical resistivity of different solders. The as-sintered solder billets with dimension of $24 \times 8 \times 10 \mathrm{~mm}$ were used as samples in electrical resistivity test. The dimension of sample was much larger than probe spacing; in this way, testing precision can be guaranteed. In accordance with previous researches, the testing current was set within the range of 100mA-1A. In order to measure the wettability of solders, the contact angle between copper substrate and solder was tested. For wettability analysis, solder balls were placed on a polished $\mathrm{Cu}$ plate with no-wash flux and heated to a temperature of $250^{\circ} \mathrm{C}$. After solidification, the contact angles were measured by a camera in the contact angle tester. For each solder, five specimens were tested, so that the reliability of the data could be ensured.

The micro-hardness of solder alloys was tested using a Vickers hardness tester (MXT-CXT) at room temperature. The applied testing load was $100 \mathrm{~g}$ while the dwell time was 20s. Thirty samples were tested for each solder system with the maximum and the minimum values were discarded. The above mentioned solder balls (with a diameter of $800 \mu \mathrm{m}$ ) were also used for shear test. These solder balls, with help of a reflow oven, were welded onto an experimental chip with copper soldering pads (the diameter of which was $600 \mu \mathrm{m})$. The ball shear test was performed on a push-pull tester (DAGE 4000-plus, Nordson Co. Ltd., U.S.). The shear height was 50 $\mu$ m while the shear speed was $25 \mu \mathrm{m} / \mathrm{s}$. After shear test, the fractography of samples were also studied using the ESEM (Quanta200) system. Additionally, by using Raman spectrometer (RAMAN), EDS and FE-SEM, the shear-fractured surface of solder balls were also studied, so as to verify the existence of the Ni-GNS in the solder matrices. 


\section{Results and discussion}

\subsection{Characterization of Ni-GNSs}

As shown in Fig 2a, folds and wrinkles were observed on the surface of initial multi-layer GNSs, which are characteristic features of thin 2-D graphene [28]. After $\mathrm{Ni}$ plating, the surface of graphene nanosheets (see Fig 2b) exhibited a grainy morphology. From the magnified images (Figs. 2c and d), it can be seen that $\mathrm{Ni}$ nanoparticles with an average diametre of $100 \mathrm{~nm}$ were successfully deposited on the surface of GNSs. Results of EDS indicated weight fractions of C and Ni in the chosen location (marked in Fig, 2d) $-6.03 \%$ and $78.88 \%$, respectively. This result helped to confirm the existence of Ni nanoparticles on the GNS surface; the elements $\mathrm{N}$ and $\mathrm{O}$ appeared in the EDS spectrum might be caused by residual reagents and oxidation.

\subsection{Microstructural characterization}

From microstructures of both plain and composite solders under as-soldered condition (Fig. 3), it can be easily found that there are considerable differences in the morphology of IMCs formed at the solder/Cu interface in different solders. For the plain SAC solder sample, the short-rod like $\mathrm{Cu}_{6} \mathrm{Sn}_{5}$ IMCs can be observed at the interface, produced by the $\mathrm{Sn}-\mathrm{Cu}$ reaction during the soldering process. However, morphologies of IMCs at composite solders $/ \mathrm{Cu}$ interfaces were altered after the doping of Ni-GNS. As can be seen in Figs. 3b-d, morphology of these IMCs manifested a transformation, from the short-rod like to a cauliflower-like. The EDS spectrum of a chosen interfacial location (shown in Fig. 3d) indicated that these newly formed IMCs consisted of $\mathrm{Sn}, \mathrm{Ni}$ and $\mathrm{Cu}$. In addition, it was also found that thickness of IMCs formed at the interfaces was also changed. In order to measure it, an image software (Image J) was employed, and the obtained results are presented in Table 2. It can be seen that the thickness magnitude of IMCs was proportional to the amount of Ni-GNS added. For instance, thickness of IMCs in the composite solder reinforced $0.2 \mathrm{Ni}-\mathrm{GNS}$ achieved $5.93 \pm 0.63 \mu \mathrm{m}$, in contrast to $4.25 \pm 0.72 \mu \mathrm{m}$ in the plain SAC solder. It has reported that the apparent activation energy of $(\mathrm{Cu}, \mathrm{Ni})_{6} \mathrm{Sn}_{5}$ was 34.6 $\mathrm{kJ} / \mathrm{mol}$, which is much lower than that of $\mathrm{Cu}_{6} \mathrm{Sn}_{5}(58.6 \mathrm{~kJ} / \mathrm{mol})$ [29]. Moreover, it was 
reported that the diffusion coefficients of $\mathrm{Cu}$ atoms and $\mathrm{Ni}$ atoms in liquid $\mathrm{Sn}$ were $1.8 \times 10-4 \mathrm{~cm}^{2} / \mathrm{s}$ and $2.3 \times 10-4 \mathrm{~cm}^{2} / \mathrm{s}$, respectively [30]. These findings indicate that $(\mathrm{Cu}, \mathrm{Ni})_{6} \mathrm{Sn}_{5}$ can easier be formed compared to $\mathrm{Cu}_{6} \mathrm{Sn}_{5}$. Essentially speaking, the formation of interfacial IMC mainly controlled by diffusion mechanism. In the present study, it is believed that a part of $\mathrm{Ni}$ nanoparticles depositing on GNSs nanosheets arrived at the solder/Cu interface, leading to the formation of $(\mathrm{Cu}, \mathrm{Ni})_{6} \mathrm{Sn}_{5}$ IMC. Therefore, the variations of IMCs in morphology and thickness might be attributed to the diffusion of Ni that introduced from the added Ni-GNS.

In addition to the microstructural variation at the solder/ $\mathrm{Cu}$ interface, microstructures in the composite solder matrix also exhibited some differences. By comparing the microstructural images shown in Fig. 3, two main features can be easily observed in the composite solder matrix - coarse $\mathrm{Ag}_{3} \mathrm{Sn}$ IMCs and the newly formed blocky IMCs. A change in the grain size of $\mathrm{Ag}_{3} \mathrm{Sn}$ IMCs was also measured with the software and the results are presented in Table 2. Apparently, the grain size of $\mathrm{Ag}_{3} \mathrm{Sn}$ exhibited an increasing trend, from $1.22 \pm 0.34 \mu \mathrm{m}$ in the plain SAC solder to $2.35 \pm 0.46 \mu \mathrm{m}$ in the $0.2 \mathrm{Ni}-\mathrm{GNS}$ composite solder. The variation in the grain size of $\mathrm{Ag}_{3} \mathrm{Sn}$ IMCs might be a result of the change in undercooling during solidification, caused by the doping of Ni-GNSs.

Newly formed blocky IMCs in the composite solder matrix were also studied. These IMCs shaped as spheres or short rods (Fig. 3b-d) were formed in the matrix after addition of Ni-GNSs. In particular, with an increase in the amount of Ni-GNSs added (from 0 to $0.2 \mathrm{wt}$ \%), these IMCs demonstrated an increase both in their quantity and volume. In order to further understand the distribution and components of these IMCs in the solder matrix, a representative SEM image of the SAC/0.2Ni-GNS solder alloy with corresponding EDS analysis is presented in Fig. 4. From the SEM image it can be found that these IMC phases (mentioned above) with a dark colour (their average size was $5.32 \pm 1.83 \mu \mathrm{m}$ ), were relatively uniformly distributed in the solder matrix. The EDS spectrum revealed that the weight fraction of $\mathrm{Ni}, \mathrm{Cu}$ and $\mathrm{Sn}$ in the chosen position were $2.69 \%, 22.75 \%$ and $50.9 \%$ respectively, this result helped to prove that the IMCs were of the $(\mathrm{Cu}, \mathrm{Ni})_{6} \mathrm{Sn}_{5}$ phase. A similar IMC phase was reported by Yang et al. [25] when studying the properties of SAC/CNT-Ni composite solder.

Moreover, it is also worth noting that appearance of $\mathrm{C}$ atoms in the EDS spectrum (Fig. 4b), which can be seen as an evidence of GNS reinforcements. Hence, 
there is a reason to believe that the deposited $\mathrm{Ni}$ nanoparticles were not completely broken away from GNS surfaces during the soldering process. As depicted in Fig. 5, $\mathrm{Ni}$ nanoparticles tend to act as a "bridge" linking GNSs and the solder matrix by forming Ni-containing IMCs. This process would eventually improve the retained ratio of GNSs in the solder joint. The influence of deposited Ni nanoparticles on IMCs composition and the retained ratio of nanosheets in the solder alloy will be further studied in our future research.

\subsection{DSC test results}

Fig. 6 illustrates the DSC results of both the plain solder and the composite solders incorporated with Ni-GNS reinforcements. It is evident that all endothermic peaks were appeared within the range of $219.25^{\circ} \mathrm{C}$ to $220.12^{\circ} \mathrm{C}$. This result indicates that the melting point of the solder alloy can hardly be influenced when the weight fraction of Ni-GNS is relatively small. In addition, it can also be known from Lindermann criterion that a material's melting point is one of its inherent features, which is determined by inter-atomic distance and the atomic mean-square displacements [31]. In this study, however, the balance the inter-atomic distance and the atomic mean-square displacements of solder alloy could hardly be changed by adding a small quantity of Ni-GNS reinforcements. Therefore, the appropriate addition of Ni-GNS will not limit the applicability of the SAC305/ Ni-GNS soler alloy by affecting its melting point significantly.

\subsection{Resistivity of plain SAC and reinforced solders}

The results of the electrical-resistivity measurements for SAC solders with various concentrations of Ni-GNS reinforcement are presented in Fig. 7. The test data of show a slight decrease in electrical resistivity with an increasing amount of Ni-GNSs. According to previous studies, volume fraction, shape, size, and type of reinforcements are main factors that largely determine the electrical resistivity of a composite material [32-35]. According to the rule proposed by Matthiessen [36], the total electrical resistivity of a material consist of three parts, including deformation 
resistivity, thermal resistivity and impurity resistivity. Through influencing the lattice scattering and impurity scattering, these three types of resistivities would disturb the normal motions of electrons so as to affect the electrical resistivity of a material. However, compared with monolithic solder alloys, the electrical resistivity of a composite solder alloy is mainly determined by impurity resistivity. Specifically, the reinforcements in composite conductive systems often work as the centers for electron scattering. Accordingly, the electrical resistivity of the composite system would be significantly influenced when the volume fraction of reinforcements is relatively high.

In this study, there was little difference between electrical resistivities of the plain solder and the Ni-GNS-reinforced composite solders. This phenomenon can be interpreted based on the effect of reinforcement's electrical resistivity and the amount of Ni-GNSs added. On the one hand, the electrical resistivities of $\mathrm{Ni}(\sim 6.84 \mu \Omega \cdot \mathrm{cm})$ and GNSs $(\sim 10 \mu \Omega \cdot \mathrm{cm})$ are both much smaller than that of the SAC solder (12.9 $\mu \Omega \cdot \mathrm{cm})$. Thus, addition of Ni-GNSs helped to lower electrical resistivity of the composite solder. On the other hand, as mentioned above, the volume fraction of reinforcement also has a considerable effect on resistivity of composites. However, in this study, relatively small amounts of Ni-GNSs used as reinforcement could hardly affect significantly the resistivity of the studied solder systems.

\subsection{Wettability measurement}

The wettablity of a solder alloy is a critical property that used to evaluate the bonding quality between solder and substrate. Generally, in the process of soldering, solder alloy which has smaller contact angle on the substrate also provide much more dependable interconnection [37]. As shown in Fig. 8, the measured contact angle decreased with addition of Ni-GNS (from $37.5^{\circ}$ for the plain SAC solder to $32.6^{\circ}$ for the SAC with 0.2 wt. \% Ni-GNSs). These test results indicate that introduction of Ni-GNS reinforcement improved wettability of the composite solders. This may be attributed to the fact that added Ni-GNS nanoparticles accumulated at the interface between the molten solder and the flux during soldering; thereby lowering the 
288 interfacial surface energy. This process decreases the interfacial tension between the

289

290

291

292

293

294

295

296

297

298

299

300

301

302

303

304

305

306

307

308

309

310

311

312

313

314

315

flux and the solder, resulting in formation of a smaller contact angle.

\subsection{Mechanical properties: Microhardness and Shear strength}

Since micro-hardness is closely related to the abrasion or wearing resistence of solder alloys, micro-hardness is usually regarded as one main item to evaluate the mechanical performance of solder alloys. Generally, factors which determine the microhardness of solder alloys mainly include microstructures, dislocation motion, chemical composition and processing temperature [38]. Fig.9 shows the average microhardness for the $0.05,0.1$ and $0.2 \mathrm{wt} \% \mathrm{SAC} / \mathrm{Ni}-\mathrm{GNS}$ composite solder alloys and the plain SAC samples. It is evident that the composite solder alloy display an increase in the microhardness values with increasing weight fraction of Ni-GNS. Compared with the plain SAC solder $(12.2 \mathrm{HV})$, the average microhardness of composite solder alloy increased up to $19.7 \%$ (reached $14.6 \mathrm{HV}$ ) with 0.2 wt. \% Ni-GNS addition. Herein, the classical dispersion strengthening theory can be employed to give explanation for the improvement in micro-hardness [39]. Based on the theory, the added foreign particles are likely to affect the deformation behaviours of solder alloys by impeding dislocation motions and grain-boundary sliding, which in turn increase the microhardness [40]. Such a phenomenon is widely known as pinning effect, which could explain the strengthing mechanism of composite materials. In the present study, the reinforcing Ni-GNSs in a core-shell form (the core is GNS while the outer shell is newly formed $\left.(\mathrm{Ni}, \mathrm{Cu})_{6} \mathrm{Sn}_{5} \mathrm{IMCs}\right)$, were found uniformly dispersed in the solder matrix (see Fig. 4a). This uniformly distributed composite reinforcement can serve as enhancing phases, inhibiting effectively mechanical deformation.

In addition to the micro-hardness test, ball shear test is another common approach to evaluate the reliability of a solder joint. In this study, ball shear test was also carried out to measure the shear strength of both plain and composite solder joints. Fig.10 shows the average shear strength and the standard deviations of the Ni-GNS doping composite solder alloys and the plain SAC samples. It can be 
observed that the average shear strength of SAC/Ni-GNS composite solder joints was obviously higher than that of the plain SAC solder joints. In particular, the average shear strength of the $0.2 \mathrm{wt} \% \mathrm{Ni}-\mathrm{GNS}$ incorporating composite solder joint reached 58.4MPa, compared with $48.8 \mathrm{MPa}$ of plain SAC solder joints. The enhancement in shear strength can also be attributed to the newly formed $(\mathrm{Ni}, \mathrm{Cu})_{6} \mathrm{Sn}_{5} \mathrm{IMC}$ and the uniformly distributed Ni-GNS in the composite solder matrix. In addition, it is expected that the excellent intrinsic mechanical strength of GNS nanosheets also made a considerable contribution to the improvement in shear strength.

\subsection{Fracture analysis}

After the ball shear test, the shear-fractured surfaces were further observed using an ESEM system to understand the failure behaviors of solder joints. Fig.11a-d show the morphologies of the fractured surfaces of both plain and composite solder joints. It can be observed that the plain SAC solder joint (Fig.11a) presents a brittle fracture pattern with a relatively smooth surface. In contrast, a ductile fracture pattern with more dimples and more rough morphology was obtained on the fractured surface of composite solder joints. Specifically, the roughness of fractured surface increases with the addition amount of Ni-GNS nanosheets increases. This transformation in fracture mode may directly benefit from the homogeneously distributed Ni-GNS nanosheets in the solder matrix.

\subsection{Verification of $\mathrm{Ni}$-GNSs reinforcement in composite solder}

Verification of existence, actual position and characterisation of structural attributes of reinforcements in the solder matrix are the main focus of research into composite solders. As the most effective tool to characterize the carbon-based materials, Raman spectroscopy was employed to identify and validate the doped Ni-GNSs in the composite solder. It was reported previously [41-42] that shear fractures often occur at the interface between intermetallic phase and Sn-rich phase in Sn-based solder matrix. In addition, according to a previous study concerning the 
343 location of the reinforcement added in the solder matrix, reinforcements are more

344 likely aggregated at IMC surface or phase interfaces [43]. Hence, the added Ni-GNSs

345 could possibly be found at shear-fracture areas. In this study, the shear-fractured

346 surfaces of solder joints were observed so as to verify the existence of the added

347 Ni-GNSs. A typical SEM image taken from a fracture surface (Fig. 12a) demonstrates

348 that there are some sheet-like substances embedded in the solder matrix.

349 According to the EDS spectrum (Fig. 12b), carbon and nickel atoms were present 350 in the chosen position, with weight ratios of $8.74 \%$ and $1.18 \%$, respectively. To 351 identify these sheet-like substances, Raman spectroscopy was employed to further 352 analyse the area of aggregation of these sheets; the obtained Raman spectrum is 353 shown in Fig. 13. In this spectrum three peaks are notable: $1363 \mathrm{~cm}^{-1}, 1586 \mathrm{~cm}^{-1}$ and $3542720 \mathrm{~cm}^{-1}$, characteristic to GNS [44]. Thus, the Raman spectrum together with the 355 results of the SEM and EDS analyses confirmed the presence of the Ni-GNSs 356 reinforcements in the matrices of the composite solders. In addition, the element 357 contents of $\mathrm{C}$ and $\mathrm{Ni}$ shown in Fig. 12b are highly consistent with the EDS result 358 provided in Fig. 4b. This finding could strongly corroborates the view that the 359 deposited Ni nanoparticles were transformed into $(\mathrm{Ni}, \mathrm{Cu})_{6} \mathrm{Sn}_{5}$ and finally stay at the 360 surface, or in the vicinity, of GNS sheets.

361

362

\section{Conclusions}

GNS nanosheets decorated with Ni nanoparticles (Ni-GNS) were prepared with the chemical reduction method, which were subsequently added as reinforcement to SAC305 through a powder metallurgy route to form composite solders. On the basis of characterization of Ni-GNSs and analyses of the microstructures as well as physical and mechanical properties of the synthesized composite solders, the primary results of this study can be summarized as follows:

1) Ni nanoparticles with diameter of approximately $100 \mathrm{~nm}$ were successfully deposited on the surface of graphene nanosheets, so as to obtain the composite reinforcement- Ni-GNSs. 
2) With addition of Ni-GNSs in the solder matrix, morphology of IMCs at the solder/Cu interface was changed from short-rod like to cauliflower-like; thickness of this interfacial IMCs was proportional to the amount of Ni-GNSs added, which could be explained by diffusion of $\mathrm{Ni}$. In addition, uniformly dispersed blocky $(\mathrm{Ni}, \mathrm{Cu})_{6} \mathrm{Sn}_{5}$ as well as the coarse $\mathrm{Ag}_{3} \mathrm{Sn}$ IMCs were observed in the solder matrix after addition of Ni-GNSs.

3) Only insignificant decline in electrical resistivity of Ni-GNS doped composite solders was found related to lower resistivity of Ni and GNS. There was also a negligible change in the melting point in Ni-GNS-reinforced solders, since nanosheets were added in relatively small amounts. However, the change in contact angle indicated that addition of nanoparticles enhanced wettability of the solder.

4) The improvements in both the microhardness and the shear strength due to the addition of the Ni-decorated graphene nanosheets were observed which can be directly attributed to the uniform dispersion of the $(\mathrm{Ni}, \mathrm{Cu})_{6} \mathrm{Sn}_{5}$ in the solder matrix.

5) The added Ni-decorated graphene nanosheets were found on the fracture surfaces after mechanical testing. The results obtained with EDS and Raman spectroscopy confirmed the existence of Ni-GNSs in the solder matrix.

\section{Acknowledgments}

The authors acknowledge the research funding by the National Nature Science Foundation of China (NSFC) and The Research Grants Council (RGC) Joint Research project (NSFC NO. 61261160498, RGC NO.CityU101/12). This research was also supported by the China-European Union technology cooperation project, No. 1110 as well as the Marie Curie International Research Staff Exchange Scheme Project within the $7^{\text {th }}$ European Community Framework Programme, No. PIRSES-GA-2010-269113 "Micro-Multi-Material Manufacture to Enable Multifunctional Miniaturised Devices (M6)". Thanks are also given to the State Key Laboratory of Materials Processing and 
399 Die \& Mould Technology and the Analytical and Testing Centre in Huazhong

400

401

402

403

404

405

406

407

408

409

410

411

412

413

414

415

416

417

418

419

420

421

422

423

424

425

426

University of Science Technology for the analytical and testing services.

\section{Reference}

[1] Y. Li, K. Moon, C.P. Wong, Electronics without Lead, Science, 308 (2005) 1419_ 1420.

[2] I.E. Anderson, Development of $\mathrm{Sn}-\mathrm{Ag}-\mathrm{Cu}$ and $\mathrm{Sn}-\mathrm{Ag}-\mathrm{Cu}-\mathrm{X}$ alloys for $\mathrm{Pb}$-free electronic solder applications, Lead-Free Electronic Solders, 18(2007) 55-76.

[3] L. Gaoa, S. Xue, L. Zhang, Z. Sheng, F. Ji, W. Dai, S. -L. Yua, G. Zeng, Effect of alloying elements on properties and microstructures of $\mathrm{SnAgCu}$ solders, Microelectronic Engineering, 87 (2010) 2025-2034.

[4] L.C. Tsaoa, C.H. Huang, C.H. Chung, R.S. Chen, Influence of $\mathrm{TiO}_{2}$ nanoparticles addition on the microstructural and mechanical properties of $\mathrm{Sn} 0.7 \mathrm{Cu}$ nano-composite solder, Materials Science and Engineering A, 545 (2012) 194-200.

[5] A. K. Gain, Y.C. Chan, W.K.C. Yung, Effect of additions of ZrO2nano-particles on the microstructure and shear strength of $\mathrm{Sn}-\mathrm{Ag}-\mathrm{Cu}$ solder on $\mathrm{Au} / \mathrm{Ni}$ metallized $\mathrm{Cu}$ pads, Microelectronics Reliability, 51 (2011) 2306-2313.

[6] A. K. Gaina, Y.C. Chan, A. Sharif, W.K.C. Yung, Effect of small Sn-3.5Ag$0.5 \mathrm{Cu}$ additions on the structure and properties of $\mathrm{Sn}-9 \mathrm{Zn}$ solder in ball grid array packages, Microelectronic Engineering, 86 (2009) 2347-2353.

[7] J. Shen, Y.C. Chan, Research advances in nano-composite solders, Microelectronics Reliability, 49 (2009) 223-234.

[8] J. -P. Salvetat-Delmotte, A. Rubio, Mechanical properties of carbon nanotubes: a fiber digest for beginners, Carbon, 40 (2002) 1729-1734.

[9] E. Saethera, S.J.V. Frankland, R.B. Pipes, Transverse mechanical properties of single-walled carbon nanotube crystals Part I: determination of elastic moduli, Composites Science and Technology, 63 (2003) 1543-1550.

[10] Ph. Mauron , Ch. Emmenegger, A. Zuttel, Ch. Nutzenadel, P. Sudan, L. Schlapbach, S ynthesis of oriented nanotube films by chemical vapor deposition, 
Carbon, 40 (2002) 1339-1344.

[11] A.A. Balandin, S. Ghosh, W. Bao, I. Calizo, D. Teweldebrhan, F. Miao, C. N. Lau, Superior thermal conductivity of single-layer graphene, Nano letter, 8 (2008) 902-907.

[12] A. Akturk, N. Goldsman, Electron transport and full-band electron-phonon interactions in graphene, Jourmal of applied physic, 103(2008) 0537021-8.

[13] C. Lee, X. Wei, J. W. Kysar, J. Hone, Measurement of the elastic properties and intrinsic strength of monolayer graphene, Science, 321 (2008) 385-388.

[14] S. Park, R. S. Ruoff, Chemical methods for the production of graphenes, Nature Nanotechnology, 4 (2009) 217-224.

[15] B. Kim, J, Im, B. Y. Lee, M. G. Sung, K. Heo, J. H. Bak, Y. D. Park, S. Hong, Carbon nanotube-metal nano-laminate for enhanced mechanical strength and electrical conductivity, Carbon, 49 (2011) 2549-2554.

[16] W. -Y. Ko, J. -W. Su, C. -H. Guo, K. -J. Lin, Extraordinary mechanical flexibility in composite thin films composed of bimetallic $\mathrm{AgPt}$ nanoparticle-decorated multiwalled carbon nanotubes, Carbon, 50 (2012) 2244-2251. [17] Z.Y. Liu, B.L. Xiao, W.G. Wang, Z.Y. Ma, Singly dispersed carbon nanotube/aluminum composites fabricated by powder metallurgy combined with friction stir processing, Carbon, 50 (2012) 1843-1852.

[18] Y. Tang, X. Yang, R. Wang, M. Li, Enhancement of the mechanical properties of graphene-copper composites with graphene-nickel hybrids, Materials Science \& Engineering A, 599 (2014) 247-254.

[19] K. Mohan Kumar, V. Kripesh, Andrew A.O. Tay, Single-wall carbon nanotube (SWCNT) functionalized Sn-Ag-Cu lead-free composite solders, Journal of Alloys and Compounds 450 (2008) 229-237.

[20] X. Hu, Y.C. Chan, K. Zhang, K.C. Yung, Effect of graphene doping on microstructural and mechanical properties of $\mathrm{Sn}-8 \mathrm{Zn}-3 \mathrm{Bi}$ solder joints together with electromigration analysis, Journal of Alloys and Compounds, 580 (2013) 162-171.

[21] X.D. Liu, Y.D. Han, H.Y. Jing, J. Wei, L.Y. Xu, Effect of graphene nanosheets reinforcement on the performance of $\mathrm{Sn}-\mathrm{Ag}-\mathrm{Cu}$ lead-free solder, Materials Science \& 
457 Engineering A, 562 (2013) 25-32.

458 [22] J. Liu, C. Andersson, Y. Gao, Q. Zhai, Recent development of nano-solder paste 459 for electronic interconnect applications, $200810^{\text {th }}$ Electronics Packaging Technology 460 Conference.

461 [23] O. Mokhtari, A. Roshanghias, R. Ashayer, H.R. Kotadia, F. Khomamizadeh, A. 462 H. Kokabi, M.P. Clode, M. Miodownik, S. H. Mannan, Disabling of Nanoparticle 463 Effects at increased temperature in nanocomposite solders, Journal of Electronic 464 Materials. 41(2012) 1907-1914.

465 [24] Z. Yang, W. Zhou, P. Wu, Effects of Ni-coated carbon nanotubes addition on the 466 electromigration of $\mathrm{Sn}-\mathrm{Ag}-\mathrm{Cu}$ solder joints, Journal of Alloys and Compounds, 581 467 (2013) 202-205

[25] Z. Yang, W. Zhou, P. Wu, Effects of Ni-Coated carbon nanotubes addition on the microstructure and mechanical properties of $\mathrm{Sn}-\mathrm{Ag}-\mathrm{Cu}$ solder alloys, Materials Science \& Engineering A, 590(2014) 295-300.

[26] A. K. Gain, Y.C. Chan, W. K.C. Yung, Effect of nano Ni additions on the structure and properties of $\mathrm{Sn}-9 \mathrm{Zn}$ and $\mathrm{Sn}-\mathrm{Zn}-3 \mathrm{Bi}$ solders in $\mathrm{Au} / \mathrm{Ni} / \mathrm{Cu}$ ball grid array packages, Materials Science and Engineering B, 162 (2009) 92-98.

[27] A.A. El-Daly, A.E. Hammad, A. Fawzy, D. A. Nasrallh, Microstructure, mechanical properties, and deformation behavior of $\mathrm{Sn}-1.0 \mathrm{Ag}-0.5 \mathrm{Cu}$ solder after $\mathrm{Ni}$ and Sb additions, Materials and Design, 43 (2013) 40-49.

477 [28] J. Wang, Z. Li, G. Fan, H. Pan, Z. Chen, D. Zhang, Reinforcement with graphene nanosheets in aluminum matrix composites, Scripta Materialia, 66 (2012) 594-597. [29] J. -W. Yoon, B.-I. Noh, B. -K. Kim, C.-C. Shur, S. -B. Jung, Wettability and interfacial reactions of $\mathrm{Sn}-\mathrm{Ag}-\mathrm{Cu} / \mathrm{Cu}$ and $\mathrm{Sn}-\mathrm{Ag}-\mathrm{Ni} / \mathrm{Cu}$ solder Joints, Journal of Alloys and Compounds, 486 (2009) 142-147.

482 [30] C.H. Mat, R.A. Swalin, Acta Mater. 8 (1960) 388-395.

[31] F. Lindemann, Physikalische Zeitschrift, 11 (1910) 609-615.

484 [32] L. Weber, C. Fischer, A. Mortensen, On the influence of the shape of randomly 485 oriented, non-conducting inclusions in a conducting matrix on the effective electrical conductivity, Acta Materialia, 51 (2003) 495-505. 
487 [33] L. Weber, Non-conducting inclusions in a conducting matrix: Influence of

488

489

490

491

492

493

494

495

496

497

498

499

500

501

502

503

504

505

506

507

508

509

510

511

512

513

514

515

516

inclusion size on electrical conductivity, Acta Materialia 53 (2005) 1945-1953.

[34] V.C. Srivastava, A. Schneider, V. Uhlenwinkel, K. Bauckhage, Effect of porosity and reinforcement content on the electrical conductivity of spray formed 2014-Al alloy + SiCp composites, Journal of Materials Science, 39 (2004) 6821-6825.

[35] M. Gupta, G. Karunasiri, M.O. Lai, Effect of presence and type of particulate reinforcement on the electrical conductivity of non-heat treatable aluminum, Materials Science and Engineering A, 219 (1996) 133-141.

[36] W.D. Callister, Materials Science and Engineering: An Introduction, 3rd ed.,Wiley- Interscience, Singapore (1994).

[37] K.N. Tu, K. Zeng, Tin-lead ( $\mathrm{SnPb})$ solder reaction in flip ship technology, Materials science and engineering R, 34 (2001) 1-58.

[38] M. Ahmeda, T. Fouzderb, A. Sharif, Influence of Ag micro-particle additions on the microstructure, hardness and tensil properties of Sn-9Zn binary eutectic solder alloy, Microelectronics reliability, 50 (2010) 1134-1141.

[39] J.W. Martin, Precipitation hardening, Butterworth Heinemann, Oxford, UK, 1998.

[40] H. Mughrabi Plastic deformation and fracture of materials. Berlin: Springer, (1993)315-322.

[41] A. K. Gain, Y.C. Chan, A. Sharif, N.B. Wongc, W. K.C. Yung, Interfacial microstructure and shear strength of Ag nano particle doped Sn-9Zn solder in ball grid array packages, Microelectronics Reliability, 49 (2009) 746-753.

[42] T. Fouzder, A. K. Gain, Y.C. Chan, A. Sharif, W. K.C. Yung, Effect of nano Al2O3additions on the microstructure, hardness and shear strength of eutectic $\mathrm{Sn}-9 \mathrm{Zn}$ solder on Au/Ni metallized Cu pads, Microelectronics Reliability, 50 (2010) 20512058.

[43] Guang Chen, Fengshun Wu, Changqing Liu, Weisheng Xia, Hui Liu, Materials Science \& Engineering A, 636 (2015) 484-492.

[44] A.C. Ferrari, J. Robertson, Raman Spectroscopy in Carbon: from Nanotubes to Diamond, Royal Society Press, London, 2004. 
Fig. 1 Schematic of preparation of Ni-decorated nanosheets

Fig. 2 (a) Intinal GNSs, (b) as-prepared Ni-GNSs, (c) magnified micrographs of Area A; (d) magnified micrographs of Area B; (e) EDS pattern of chosen location Fig. 3 Microstructures near interfaces of $\mathrm{Cu}$ substrate with SAC (a), SAC/0.05Ni-GNS (b), SAC/0.1Ni-GNS (c) and SAC/0.2Ni-GNS (d) solders Fig. 4 (a) Representative image of distribution of $\left(\mathrm{Cu}, \mathrm{Ni}_{6}\right)_{6} \mathrm{Sn}_{5}$ in SAC/0.2Ni-GNS solder matrix; (b) corresponding EDS spectrum in chosen location Fig. 5 Supposed forms of Ni-GNS in solder matrix before (a) and after (b) soldering Fig. 6 DSC curves for different solders: (a) SAC; (b) SAC/0.05Ni-GNS; (c) SAC/0.1Ni-GNS;（d） SAC/0.2Ni-GNS

Fig. 7 Effect of volume fraction of Ni-GNSs on electrical resistivity of SAC solders Fig.8 Effect of volume fraction of Ni-GNSs on contact angles of SAC alloys

Fig. 9 Effect of volume fraction of Ni-GNSs on microhardness of nanocomposite solders

Fig. 10 Effect of volume fraction of Ni-GNSs on shear strength of nanocomposite solders

Fig.11 SEM of fracture surfaces of SAC solder joints with different fractions of Ni-GNS reinforcement (in wt.\%): (a) 0; (b) 0.05; (c) 0.1; (d) 0.2

Fig.12 (a) Typical SEM image of Ni-GNS agglomeration located at bottom of dimple after shear test, (b) corresponding EDS spectra for selected area marked in (a)

Fig. 13 Raman spectrum of chosen area in Fig. 12 (a) 
547 Table 1 The components of plating solution and experimental condition

548 Table 2 Average thickness of IMCs at interfaces and average grain size of $\mathrm{Ag}_{3} \mathrm{Sn}$ 
Table 1 The components of plating solution and experimental condition

\begin{tabular}{llll}
\hline Bath composition & \multicolumn{3}{c}{ Plating condition } \\
\hline $\mathrm{NiSO}_{4} \cdot 7 \mathrm{H}_{2} \mathrm{O}$ & $25 \mathrm{~g} / \mathrm{L}$ & $\mathrm{pH}$ & 10 \\
$\mathrm{~N}_{2} \mathrm{H}_{4} \cdot \mathrm{H}_{2} \mathrm{O}$ & $30 \mathrm{~g} / \mathrm{L}$ & Temperature $(\mathrm{T})$ & $90^{\circ} \mathrm{C}$ \\
Sodium tartrate & $10 \mathrm{~g} / \mathrm{L}$ & Ultrasonic power & $90 \mathrm{~W}$ \\
Sodium citrate & $30 \mathrm{~g} / \mathrm{L}$ & Time & $30 \mathrm{~min}$ \\
$\left(\mathrm{NH}_{4}\right)_{2} \mathrm{SO}_{4}$ & $50 \mathrm{~g} / \mathrm{L}$ & GNS powder & $0.5 \mathrm{~g} / \mathrm{L}$ \\
$\mathrm{NH}_{3} \cdot \mathrm{H}_{2} \mathrm{O}$ & $5 \%$ & & \\
\hline
\end{tabular}




\section{ACCEPTED MANUSCRIPT}

Table 2 Average thickness of IMCs at interfaces and average grain size of $\mathrm{Ag}_{3} \mathrm{Sn}$

\begin{tabular}{cccc}
\hline Sample & Addition (wt. \%) & Average thickness of IMC $(\mu \mathrm{m})$ & Average size of $\operatorname{Ag}_{3} \operatorname{Sn}(\mu \mathrm{m})$ \\
\hline SAC & Nil & $4.25 \pm 0.72$ & $1.22 \pm 0.34$ \\
1 & 0.05 & $4.59 \pm 0.65$ & $1.39 \pm 0.47$ \\
2 & 0.1 & $5.24 \pm 0.48$ & $1.68 \pm 0.53$ \\
3 & 0.2 & $5.93 \pm 0.63$ & $2.35 \pm 0.46$ \\
\hline
\end{tabular}


Initial GNS nanosheets

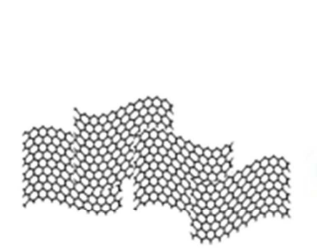

Ultrasonic dispersion

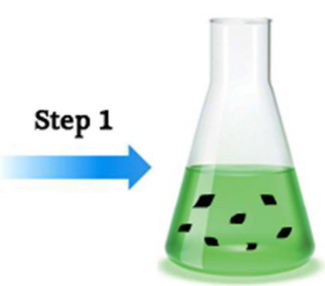

Ni-coated GNS

$\square$ : Ethanol solution

$\square$ : $\mathrm{SnCl}_{2}$ solution

$\square$ : $\mathrm{PdCl}_{2}$ solution

$\square$ : Ni plating solution

$\square$ : GNS nanosheets

: Ni nanoparticles

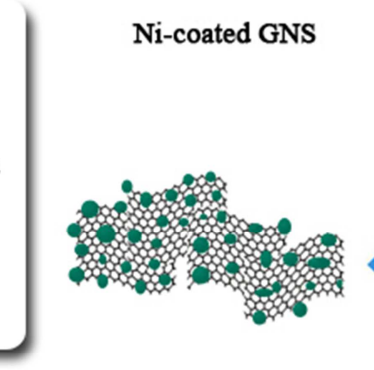

Electroless nickel plating

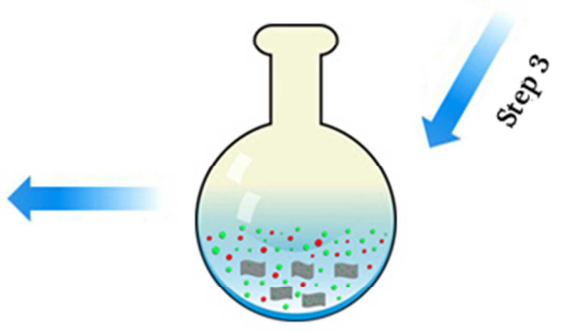

Fig. 1 Schematic of preparation of Ni-decorated nanosheets 


\section{ACCEPTED MANUSCRIPT}
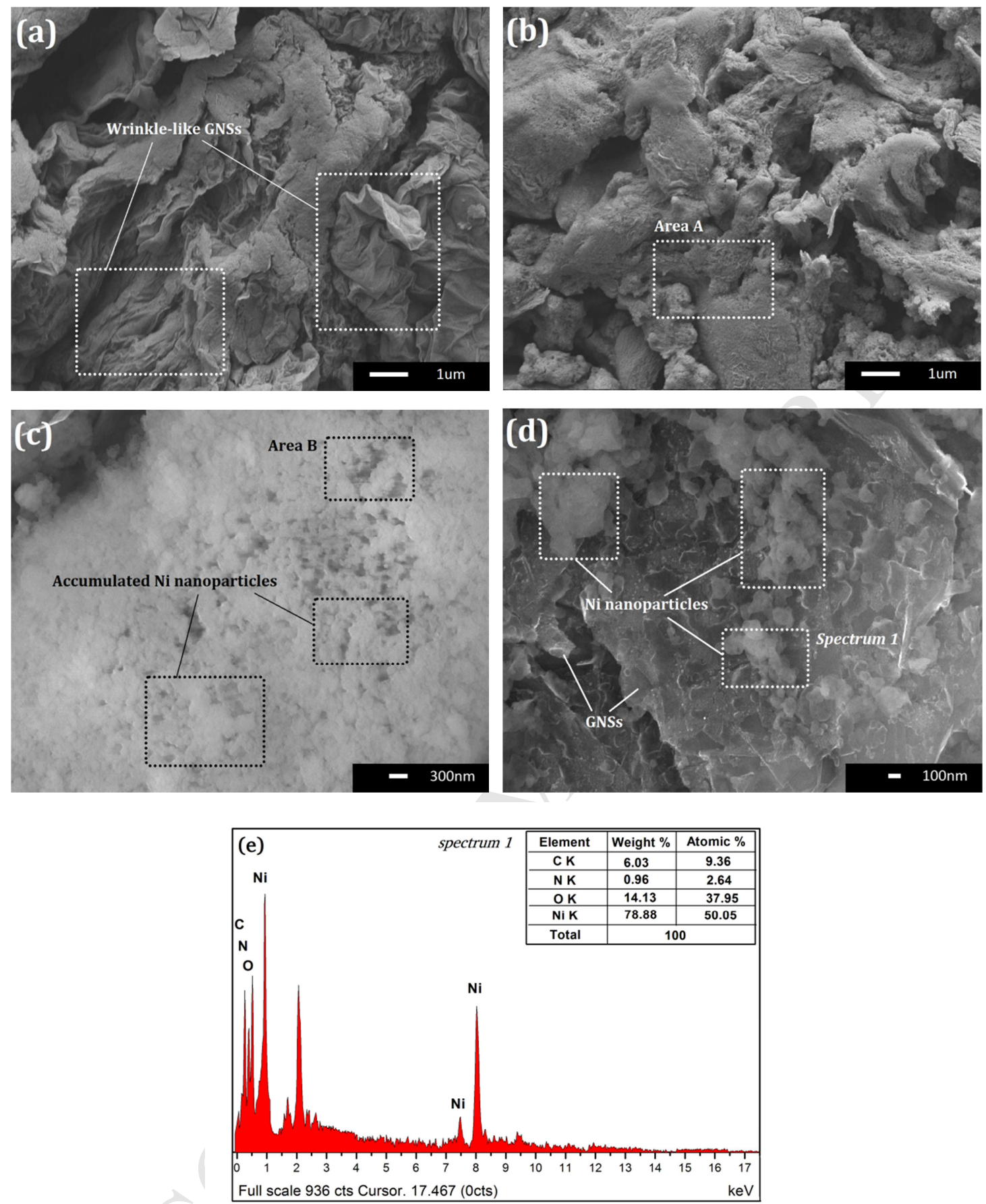

Fig. 2 (a) Intinal GNSs, (b) as-prepared Ni-GNSs, (c) magnified micrographs of Area A; (d) magnified micrographs of Area B; (e) EDS pattern of chosen location 

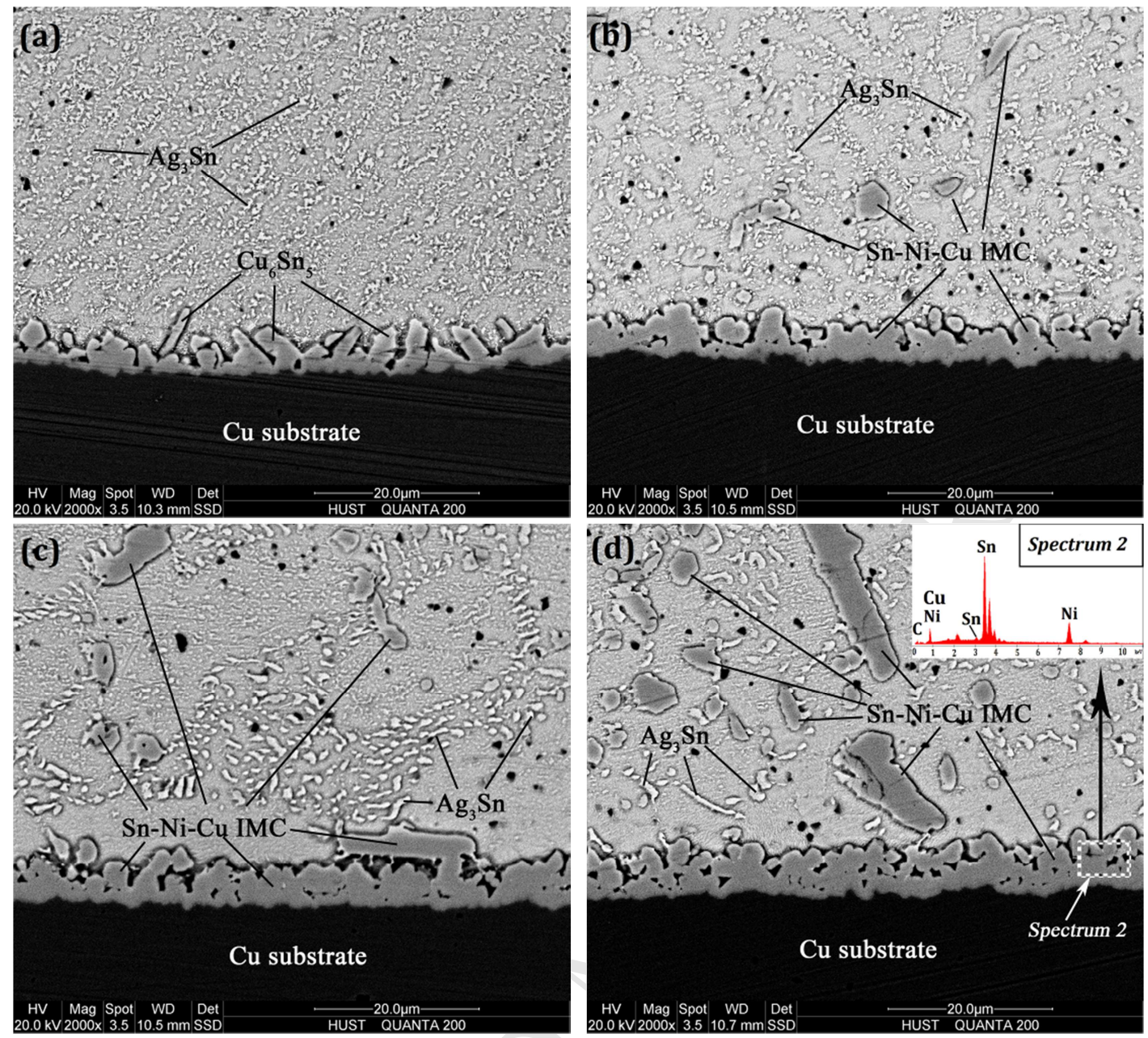

Fig. 3 Microstructures near interfaces of $\mathrm{Cu}$ substrate with SAC (a),

SAC/0.05Ni-GNS (b), SAC/0.1Ni-GNS (c) and SAC/0.2Ni-GNS (d) solders 

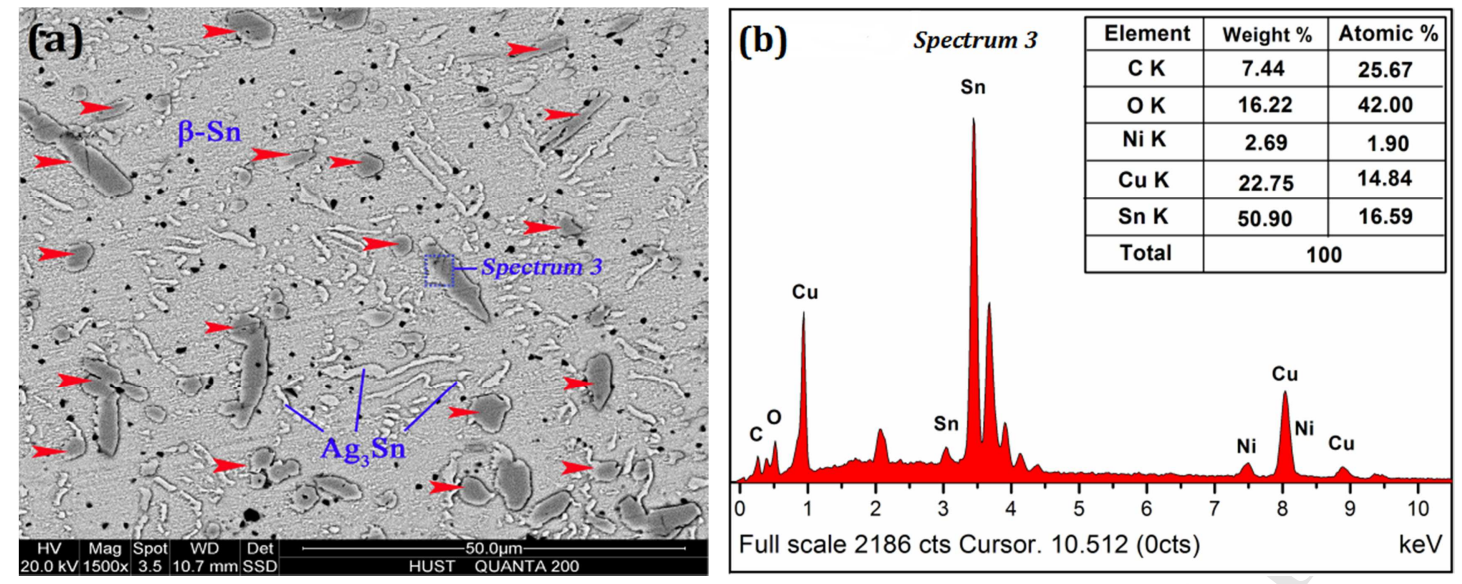

Fig. 4 (a) Representative image of distribution of $\left(\mathrm{Cu}, \mathrm{Ni}_{6} \mathrm{Sn}_{5}\right.$ in SAC/0.2Ni-GNS solder matrix; (b) corresponding EDS spectrum in chosen location 

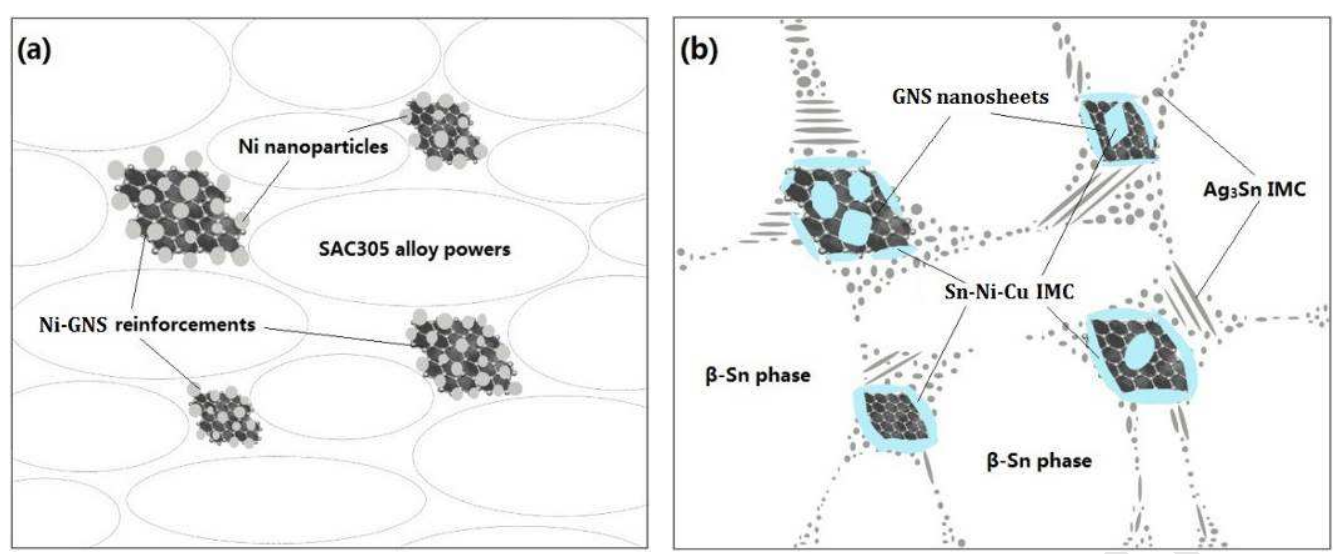

Fig. 5 Supposed forms of Ni-GNS in solder matrix before (a) and after (b) soldering 
(a)

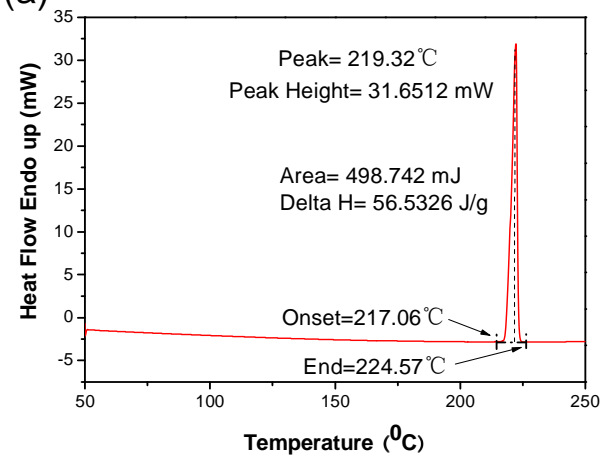

(c)

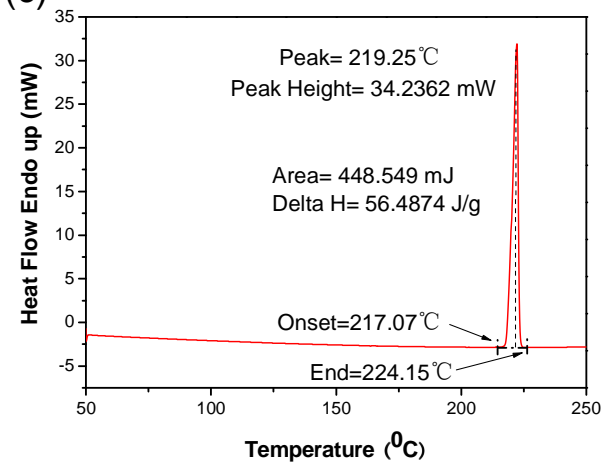

(b)

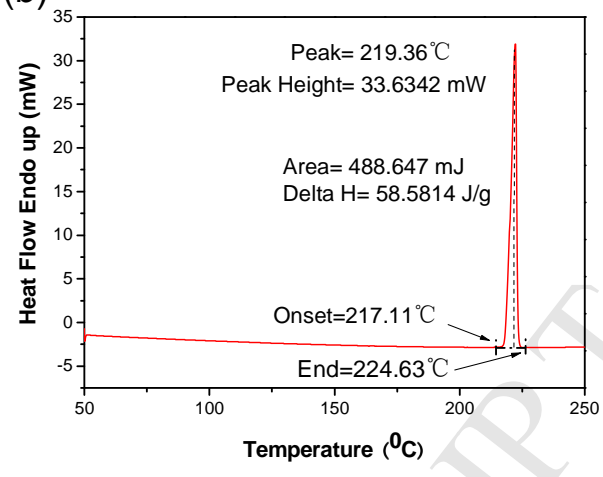

(d)

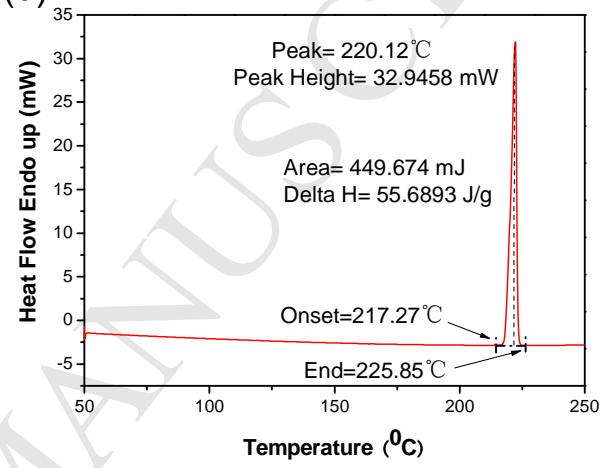

Fig. 6 DSC curves for different solders: (a) SAC; (b) SAC/0.05Ni-GNS; (c) SAC/0.1Ni-GNS; (d) SAC/0.2Ni-GNS 


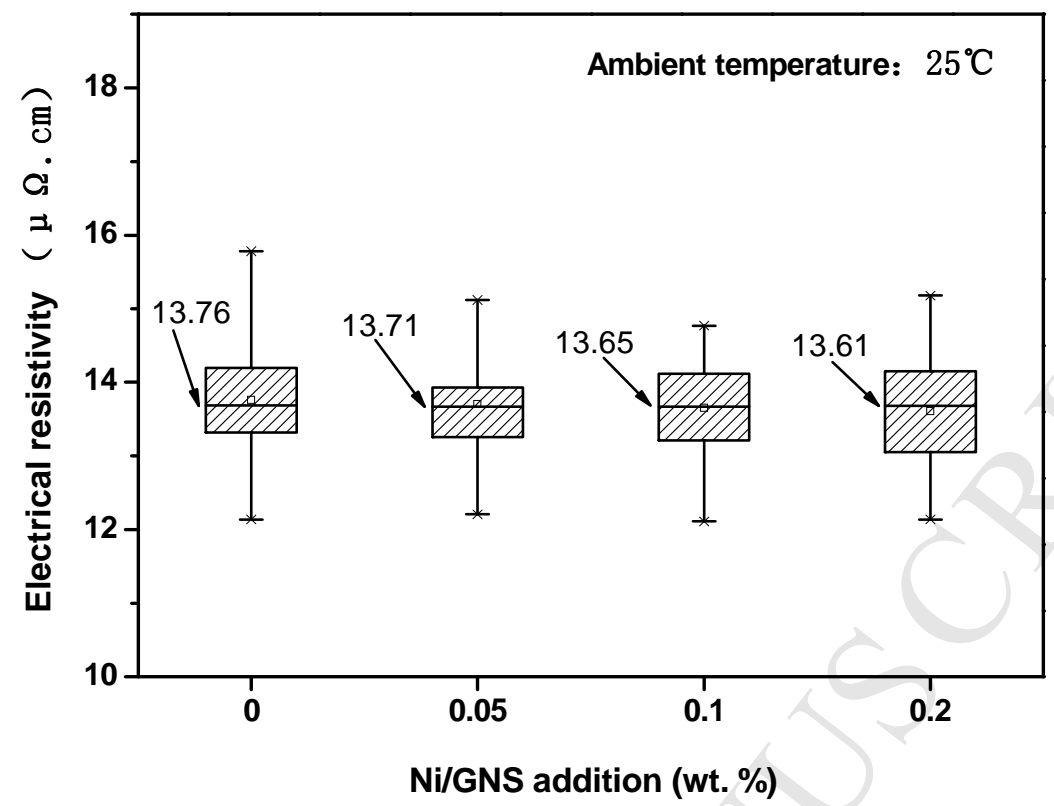

Fig. 7 Effect of volume fraction of Ni-GNSs on electrical resistivity of SAC solders 


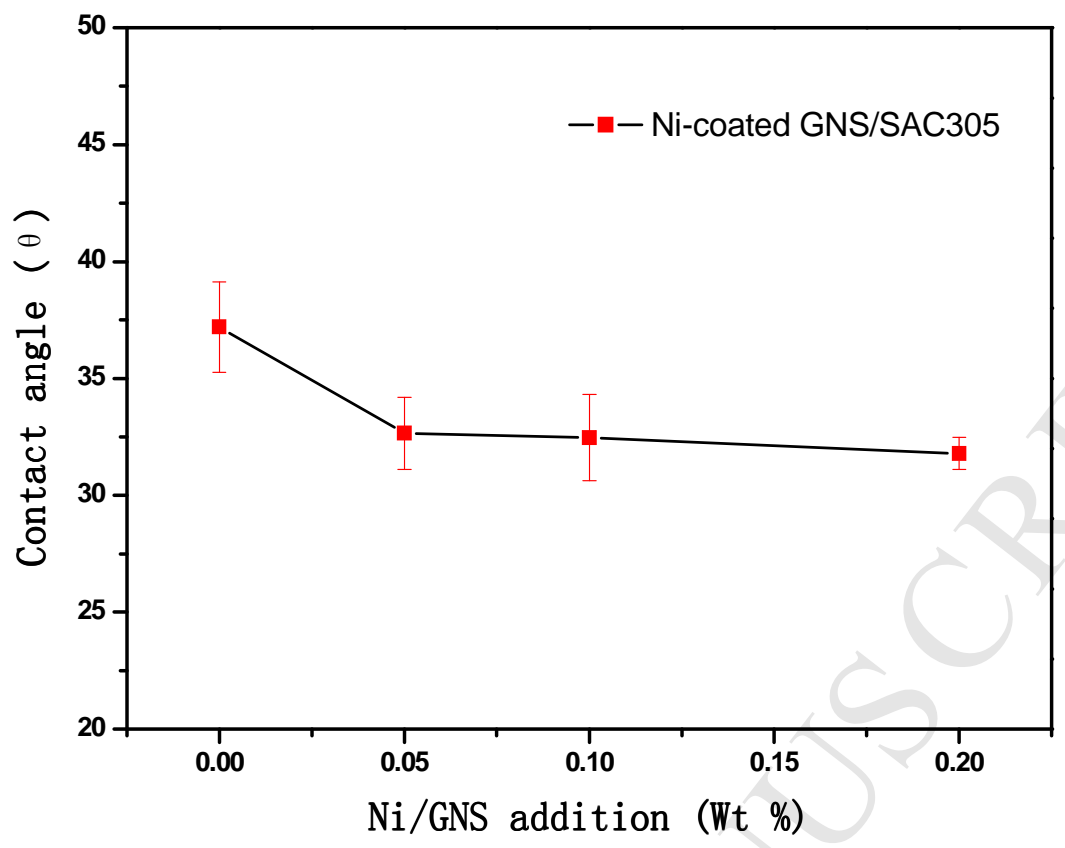

Fig.8 Effect of volume fraction of Ni-GNSs on contact angles of SAC alloys 


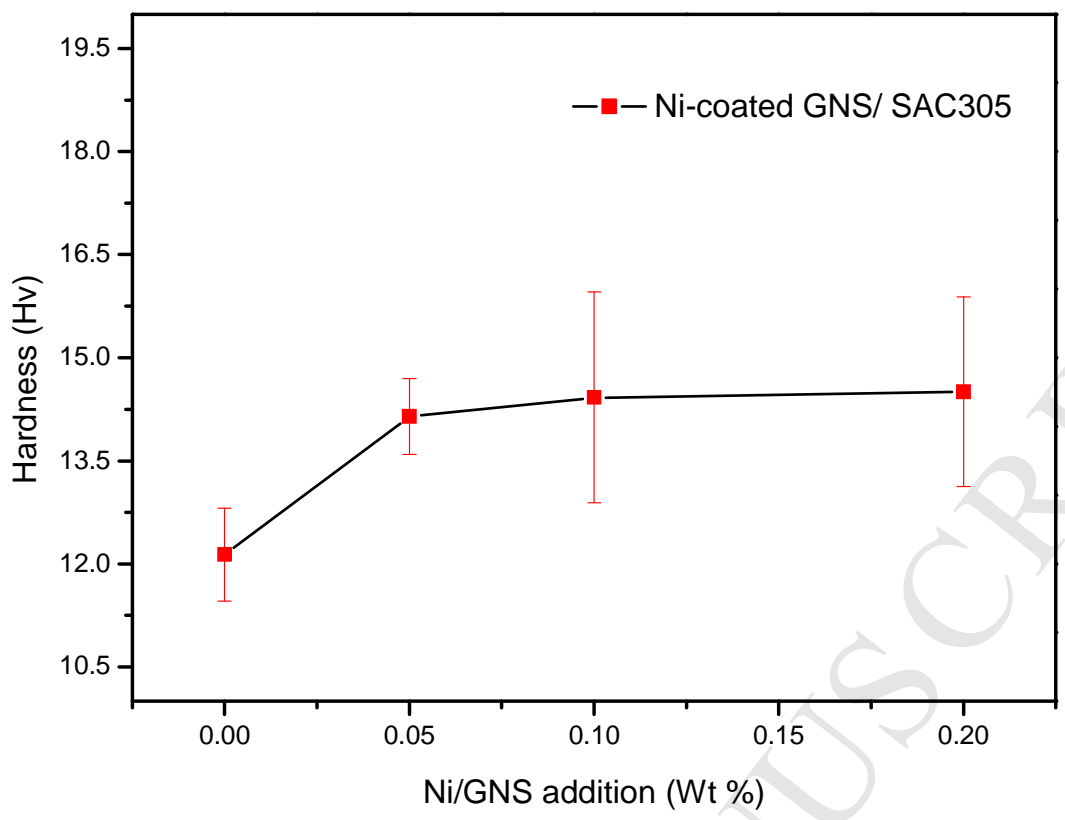

Fig. 9 Effect of volume fraction of Ni-GNSs on microhardness of nanocomposite solders 


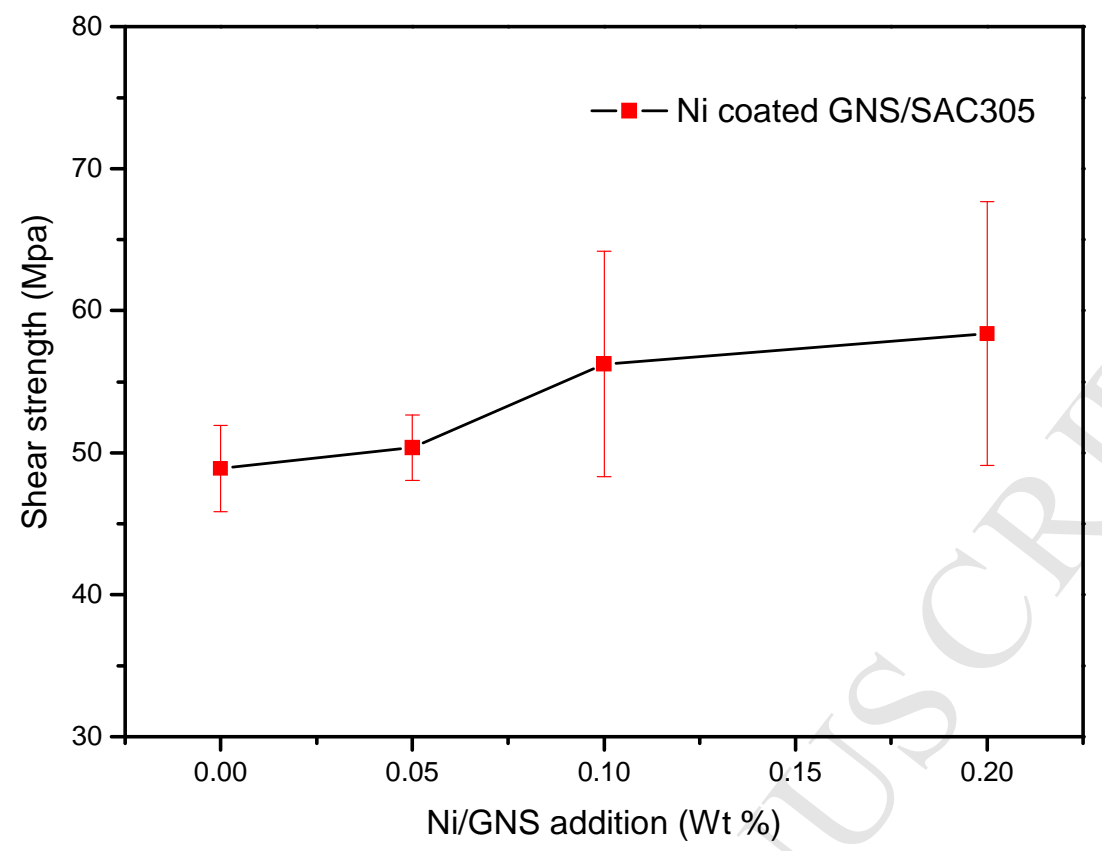

Fig. 10 Effect of volume fraction of Ni-GNSs on shear strength of nanocomposite solders 

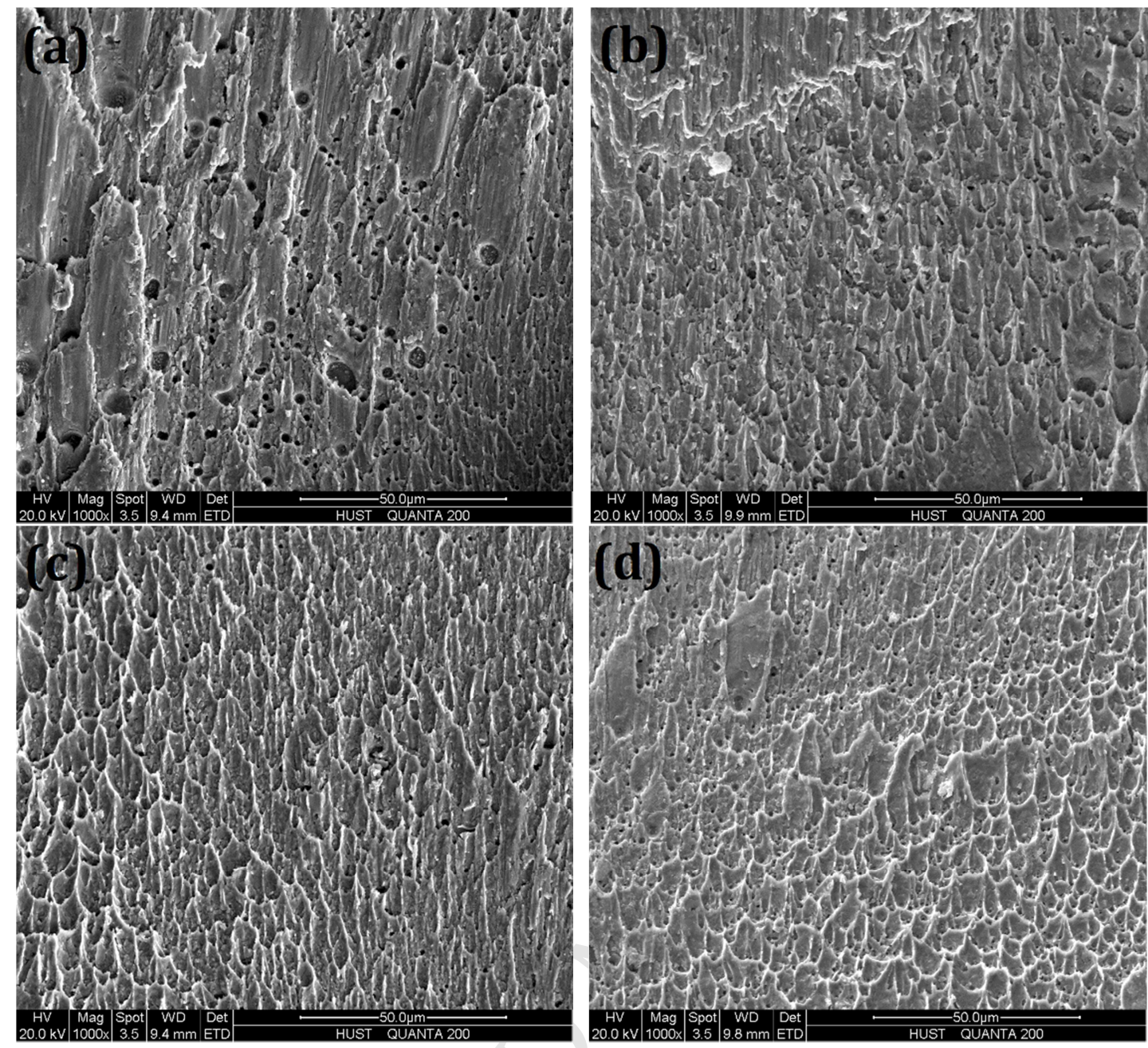

Fig.11 SEM of fracture surfaces of SAC solder joints with different fractions of Ni-GNS reinforcement (in wt.\%): (a) 0; (b) 0.05; (c) 0.1; (d) 0.2 

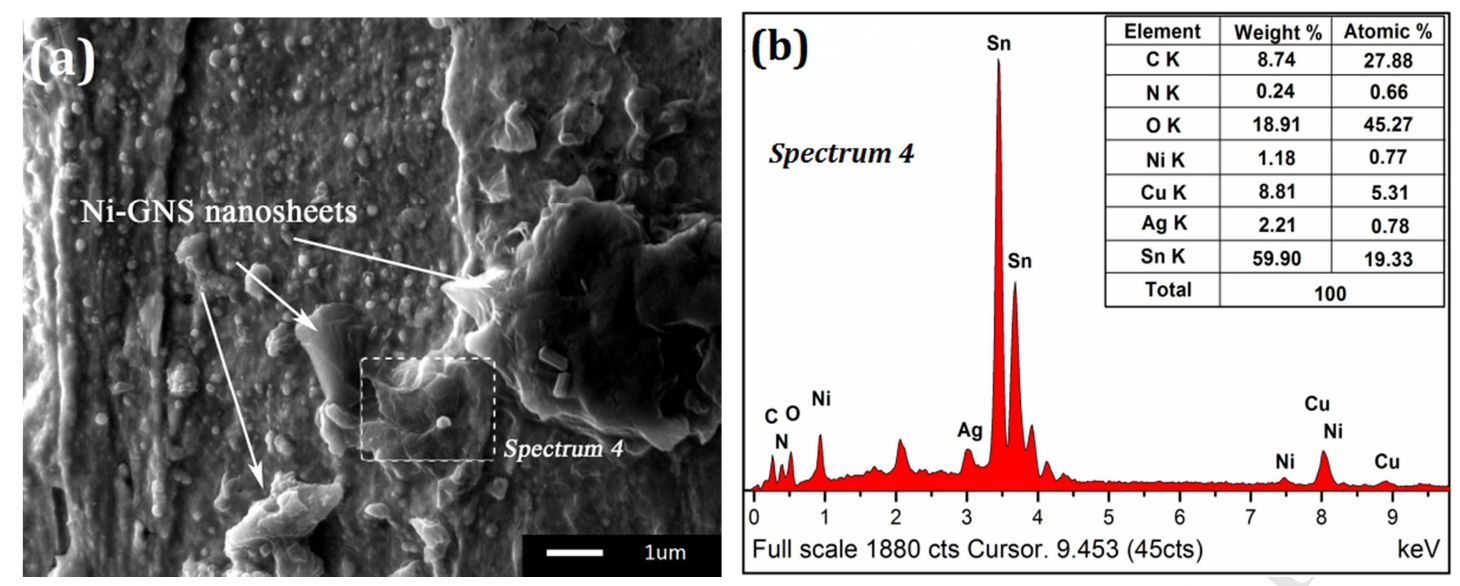

Fig.12 (a) Typical SEM image of Ni-GNS agglomeration located at bottom of dimple after shear test, (b) corresponding EDS spectra for selected area marked in (a) 


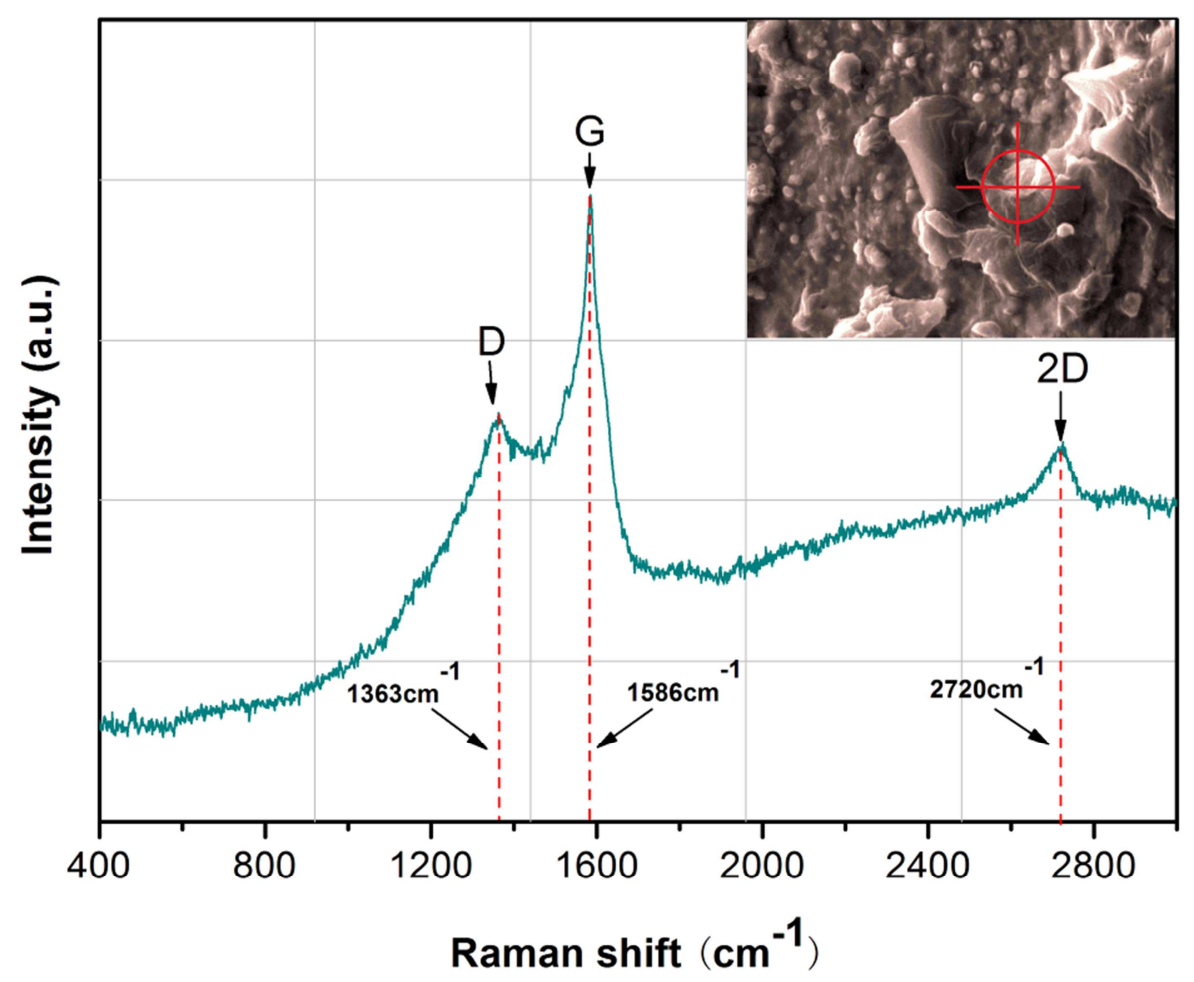

Fig. 13 Raman spectrum of chosen area in Fig. 12 (a) 


\section{Highlights}

1. Ni-coated graphene (Ni-GNS) composite reinforcement was prepared by electroless plating method.

2. Ni-GNS/SAC305 composite solders were further prepared through powder metallurgic route.

3. Microstructures, solderability and mechanical properties of this newly made composite solder were extensively studied.

4. The existence and distribution of the added reinforcement were confirmed. 